\section{Mutant flu: preparing for a pandemic}

We at the global humanitarian organization Save the Children agree that controversy over labcreated $\mathrm{H} 5 \mathrm{~N} 1$ avian influenza virus should not detract from the larger concern of global preparedness for a flu pandemic (Nature 482, 131; 2012).

In a pandemic flu situation, when all countries and responding organizations are stricken, we think it is unrealistic to hope that the most resourcepoor communities around the world will receive adequate supplies of vaccine, antivirals or antibiotics. We believe in preparing now so that community leaders, and the organizations working with them, can mitigate the effects of a severe wave of flu in the absence of substantial outside resources.

As the World Health Organization has noted, nonpharmaceutical interventions such as quarantine are crucial for an effective response, and may sometimes be the only means of delaying the spread of flu. Yet most national plans lack practical operational considerations (see go.nature.com/mi9sr3).

Detailed authoritative guidance on reducing flu transmission at household and community levels, and on the home-based care of flu patients, in low-resource settings is the most important, and needs to be published. Support should also be provided to governments in developing countries to adapt this guidance for their settings.

We believe that such efforts should be an urgent priority, and are concerned about this apparent gap in the most basic level of pandemic preparedness. Eric S. Starbuck Save the Children, Westport, Connecticut, USA. estarbuck@savechildren.org

\section{Mutant flu: assessing biosecurity risks}

In the ongoing controversy over the mutant $\mathrm{H} 5 \mathrm{~N} 1$ avian influenza research (Nature 481, 9-10, 2012), we should be wary of reducing biosecurity measures merely to assigning access rights to sensitive information and materials. A national security body made up of military and law-enforcement officials that puts confidentiality stamps on dual-use research is not in the long-term interest of scientific progress.

Biosecurity in research needs to be integrated into a more comprehensive strategy if it is to be effective and avoid harming public-health interests.

As a member and chair of several ethics-review panels of dual-use research for the European Union, I believe that these research projects, and their clearly foreseeable implications, should have undergone a proper riskbenefit assessment before funding. They could then have been modified to accommodate additional risk-management procedures.

For example, threats to biosecurity could have been minimized by developing diagnostic kits for early detection and surveillance of the new genetic variants, and by testing possible treatment strategies. It seems that none of this was done.

Johannes Rath University of Vienna, Austria.

johannes.rath@univie.ac.at

\section{Questionable use of chimpanzees}

By conducting their experiments at US chimpanzee centres, foreign scientists have been circumventing their own nations' bans on chimpanzee research since 2005 (Nature 482, 132; 2012). It is important to point out that those scientists are almost all employed by foreign-based drug companies - as reported by a US National Institutes of Health representative at the Institute of Medicine (IOM) public hearing in May 2011.
The US Food and Drug Administration's Office of New Drugs reported to the IOM committee in June 2011 that chimps are never required for preclinical drug testing in the United States, and that the agency discourages the use of chimps for this purpose. The IOM's report Chimpanzees in Biomedical and Behavioral Research, released in December 2011, also concludes that chimps are unnecessary for preclinical drug testing.

The use of chimps for preclinical drug trials in US centres by foreign drug companies is therefore contrary to US practice and should be banned.

John J. Pippin Physicians Committee for Responsible Medicine, Washington DC, USA. jpippin@pcrm.org

\section{Sugar: there's more to the obesity crisis}

To describe sugar as "toxic" is extreme, as is its ludicrous comparison with alcohol (Nature 482, 27-29; 2012). Such sensationalism could damage the livelihoods of thousands of people working in the sugar industry worldwide, and will be felt in countries such as Australia, the United States, Fiji, Mauritius, Indonesia and India.

As the senator for Queensland, Australia, where sugar is the most significant agricultural crop, I wish to voice the industry's concerns. Consumers should be assured that sugar is a safe ingredient and suitable for consumption as part of a balanced diet.

Nutritionist Jennie BrandMiller of the University of Sydney is not alone in her disgust that you published this opinion piece (The Australian, 4 February 2012). The Dietitians Association of Australia believes that it is simplistic and unhelpful to blame sugar alone for the obesity crisis.

Alan Barclay of the Australian
Diabetes Council notes in the same article in The Australian that sugar consumption in Australia has dropped by $23 \%$ since 1980 . But he adds that during that time, the number of overweight or obese people has doubled, while diabetes has tripled.

A literature review by Australia's National Health Medical Research Council, together with its draft dietary guidelines of December 2011, found that the evidence to support advice on added sugar and obesity was "limited, inconclusive or contradictory".

Robert Lustig et al. have stimulated debate, yet have unnecessarily tarnished the image of sugar. There is no evidence to suggest that reducing sugar consumption will halt the rise in obesity. The contributing factors are far more complex.

Ron Boswell Brisbane, Queensland, Australia. senator.boswell@aph.gov.au

\section{Sugar: fruit fructose is still healthy}

Robert Lustig and colleagues argue that sugar is "toxic" (Nature 482, 27-29; 2012), focusing on the "deadly effect" of the fructose moiety of sucrose. But they are directing attention away from the problem of general overconsumption.

Guidelines on healthy eating encourage fruit consumption, and fruit and fruit products are the third-largest source of fructose in the US diet.

Our meta-analyses of controlled feeding trials indicate a net metabolic benefit, with no harmful effects, from fructose at a level of intake obtainable from fruit (J. L. Sievenpiper et al. Br. J. Nutr., in the press).

John L. Sievenpiper, Russell J. de Souza, David J. A. Jenkins St Michael's Hospital, Toronto, Ontario, Canada. john.sievenpiper@utoronto.ca 